\title{
Inovações em resina composta: uma revisão de literatura
}

\section{Composite resin innovations: a literature review \\ Innovaciones en resina compuesta: una revisión de la literatura}

Lucas Dantas Rodrigues ORCID: https://orcid.org/0000-0002-0710-7500 Centro Universitário Católica de Quixadá, Brasil

E-mail: lucasdantasr@hotmail.com

Iury Alves Costa

ORCID: https://orcid.org/0000-0002-9226-3355 Centro Universitário Católica de Quixadá, Brasil

E-mail: iuryalvescosta@gmail.com

Zidane Hurtado Rabelo

ORCID: https://orcid.org/0000-0002-4671-2578 Centro Universitário Católica de Quixadá, Brasil

E-mail: zidanerabelo@gmail.com

Lucas Lino de Oliveira

ORCID: https://orcid.org/0000-0001-5586-3282 Centro Universitário Católica de Quixadá, Brasil

E-mail: lucaslinodo@gmail.com

Rayanna Mayra Feitosa Monteiro ORCID: https://orcid.org/0000-0002-1524-0950 Centro Universitário Católica de Quixadá, Brasil E-mail: rayannamayrafm@gmail.com

Henrique Cabral Sá

ORCID: https://orcid.org/0000-0001-5539-5837

Centro Universitário Católica de Quixadá, Brasil E-mail: henriquecabralhcs@gmail.com

Maria Clara Ayres Estellita ORCID: https://orcid.org/0000-0003-2650-0348 Universidade Federal do Ceará, Brasil

E-mail: mclaraestellita@gmail.com

Karlos Eduardo Rodrigues Lima ORCID: https://orcid.org/0000-0003-3127-9772 Centro Universitário Católica de Quixadá, Brasil E-mail: karlosed99@gmail.com

Marcelo Victor Sidou Lemos ORCID: https://orcid.org/0000-0002-2993-534X

Universidade Federal do Ceará, Brasil

E-mail: marcelosidou @ hotmail.com

Natasha Muniz Fontes

ORCID: https://orcid.org/0000-0002-0502-0364 Centro Universitário Católica de Quixadá, Brasil

E-mail: natashafontes@hotmail.com

Raul Anderson Domingues Alves da Silva ORCID: https://orcid.org/0000-0002-7625-3595 Universidade Federal do Ceará, Brasil

E-mail: raulalves@unicatolicaquixada.edu.br

Pedro Henrique Chaves Isaias ORCID: https://orcid.org/0000-0003-4399-1302 Universidade Federal do Ceará, Brasil E-mail: ph.isaias@yahoo.com.br

Talita Arrais Daniel Mendes

ORCID: https://orcid.org/0000-0003-3519-3618 Universidade Federal do Ceará, Brasil E-mail: talita_arrais@hotmail.com

Ernanda Maria de Araújo Sales ORCID: https://orcid.org/0000-0001-9067-3564 Universidade Federal do Ceará, Brasil E-mail: ernandasalles@yahoo.com.br 


\begin{abstract}
Resumo
O presente estudo objetivou revisar a literatura acerca da incorporação de substâncias para aprimorar as propriedades mecânicas, químicas e ópticas dos compósitos. Para tanto, foi realizada uma busca na base de dados PubMed, utilizando o descritor "Composite Resins" combinado através do operador booleano AND com cada um dos seguintes descritores "Anti-bacterial Agents", "Bulk Fill", "Fillers" e "Photoinitiators". Foram selecionados 11 artigos na língua inglesa. Existem resinas incorporadas por biovidro (BV) que reduzem a penetração de biofilme em espaços marginais dos compósitos. Estudos mostraram que a integração de metacrilatos e nanopartículas de fosfato de cálcio amorfo (NACP) favoreciam na ação antibacteriana, bem como na remineralização. Outro autor fundamentou o desenvolvimento de um compósito dentinário auto-reparável, bem como, a incorporação de dimetilaminohexadecil metacrilato de amônio quaternário (DMAHDM) que reduziu o crescimento de biofilme sem comprometer as propriedades mecânicas. Desse modo, constata-se a positiva e eficaz evolução dos compósitos resinosos favorecendo melhorias nas propriedades físicas e químicas. Entretanto, não há uma unanimidade de qual compósito garante suprimir todas as limitações.
\end{abstract}

Palavras-chave: Materiais dentários; Antibacterianos; Bulk fill.

\begin{abstract}
The present study aimed to review the literature on the incorporation of substances to improve the mechanical, chemical and optical properties of composites. For this purpose, a search was performed in the PubMed database, using the descriptor "Composite Resins" combined through the Boolean operator AND with each of the following descriptors "Anti-bacterial Agents", "Bulk Fill", "Fillers" and "Photoinitiators ". Eleven articles in English were selected. There are resins incorporated by bioglass (BV) that reduces the penetration of biofilm in marginal spaces of composites. Studies have shown that the integration of methacrylates and nanoparticles of amorphous calcium phosphate (NACP) favored the antibacterial action, as well as remineralization. Another author, supported the development of a self-repairing dental composite, as well as the incorporation of dimethylaminohexadecyl quaternary ammonium methacrylate (DMAHDM) that reduced the growth of biofilm without compromising its mechanical properties. Thus, there is a positive and effective evolution of resin composites, favoring improvements in physical and chemical properties. However, there is no unanimity as to which composite guarantees to eliminate all limitations.
\end{abstract}

Keywords: Dental materials; Antibacterials; Bulk fill.

\title{
Resumen
}

El presente estudio tuvo como objetivo revisar la literatura sobre la incorporación de sustancias para mejorar las propiedades mecánicas, químicas y ópticas de los composites. Para ello, se realizó una búsqueda en la base de datos PubMed, utilizando el descriptor "Resinas compuestas" combinado a través del operador booleano Y con cada uno de los siguientes descriptores "Agentes antibacterianos", "Bulk Fill", "Fillers" y "Fotoiniciadores ". Se seleccionaron once artículos en inglés. Existen resinas incorporadas por biovidrio (BV) que reduce la penetración del biofilm en los espacios marginales de los composites. Los estudios han demostrado que la integración de metacrilatos y nanopartículas de fosfato cálcico amorfo (NACP) favoreció la acción antibacteriana, así como la remineralización. Otro autor, apoyó el desarrollo de un composite dental autorreparador, así como la incorporación de metacrilato de dimetilaminohexadecil amonio cuaternario (DMAHDM) que redujo el crecimiento de biofilm sin comprometer sus propiedades mecánicas. Así, existe una evolución positiva y efectiva de los composites de resinas, favoreciendo mejoras en las propiedades físicas y químicas. Sin embargo, no hay unanimidad en cuanto a qué compuesto garantiza eliminar todas las limitaciones.

Palabras clave: Materiaales dentales; Antibacterianos; Bulk fill.

\section{Introdução}

No decorrer dos anos, a odontologia passou por inúmeras transformações em seus conceitos, onde a estética juntamente com a procura por tratamentos mais conservadores ganharam destaque (Cramer et al., 2011). Nesse contexto, a resina composta (RC), é um dos materiais mais pesquisados nas duas últimas décadas devido sua versatilidade, consolidandose como o material de primeira escolha para restaurações dentárias de forma direta (Ferracane, 2011).

Entretanto, até chegar à formulação atual das RCs muitos estudos tentaram correlacionar estética, propriedade de união ao substrato dentário, bem como boas propriedades mecânicas (Yamamoto et al., 2009). Atualmente as RCs apresentam uma matriz orgânica, composta por monômeros, iniciadores e modificadores de cor, uma matriz inorgânica, composta pelas partículas de carga, e um agente de união, que na maioria das vezes é o silano. Elas podem ser classificadas quanto a sua viscosidade, forma de inserção, forma de ativação e ao tamanho das partículas de carga (Reis et al., 2007). A composição 
desses materiais está diretamente relacionada às suas propriedades mecânicas. Dessa forma, com o aumento da matriz inorgânica, ocorre a redução da contração de polimerização, da absorção de água e do coeficiente de expansão linear, bem como a resistência à compressão, ao desgaste e à tração e o módulo de elasticidade são aumentados (Lin et al., 2013). Ainda, sendo importantes nas cargas intra-orais as quais são submetidas durante a mastigação, apresentando efeito direto sobre o desempenho das restaurações dentárias (Silva, 2011).

Dentre as complicações que acercam as RCs, destaca-se um dos principais fatores responsáveis pelas falhas que ocorrem comumente nas restaurações realizadas com materiais resinosos, o stress gerado pela contração de polimerização. As resinas compostas da atualidade, após a polimerização, perdem entre 2\% a 3\% de todo o seu volume (Da Silva et al., 2017). Essa perda pode acarretar em alterações fortemente comprometedoras a nível micro e macroscópico, influenciando diretamente na qualidade e durabilidade do procedimento restaurador (Guimarães, 2018).

Ademais, tratando-se sobre a influência dos fotoiniciadores nas propriedades mecânicas de uma resina composta, é possível perceber que apesar de tais substâncias corresponderem a uma pequena porção da matriz resinosa, elas possuem certa relevância, e neste aspecto, a canforoquinona (CQ) é comumente incorporada às resinas compostas como um fotoiniciador (Bertolo, 2017). Apesar de ser detentora de uma vantagem determinante para os compósitos, a CQ por ser considerada um fotoiniciador tipo II, necessita de um coiniciador que usualmente é uma amina terciária, na qual pode oxidar ao longo do tempo e cuja oxidação termina por alterar a coloração do compósito, afetando a estética e o tempo de vida útil das restauraçães (Sinhoreti, 2018).

Diversos estudos têm propostos inovações na formulação e, consequentemente, no desempenho das RCs (Souza et al., 2017). A incorporação de novos fotoiniciadores, monômeros e partículas de carga na composição das RCs proporciona uma nova perspectiva para odontologia restauradora, visando o aumento da longevidade das restaurações, a redução do tempo clínico e uma estética ainda mais favorável (Machado et al., 2018). Diante desse contexto, à medida que as propriedades estéticas e mecânicas das RCs são melhoradas, a técnica restauradora tem sido investigada para adequar-se às novas exigências (Soares et al., 2019).

Assim, o presente estudo objetivou revisar a literatura acerca das inovações empregadas na formulação das RCs, bem como elucidar a importância da incorporação desses agentes para a melhoria das propriedades estéticas e mecânicas das mesmas.

\section{Metodologia}

Trata-se de um estudo de revisão de literatura, de natureza qualitativa e descritiva (Pereira et al., 2018), realizada por meio da análise de estudos que abordaram mudanças inovadoras na composição de resinas compostas (RC's) e avaliaram o resultado da combinação desses, descrevendo o cumprimento ou não dos princípios fundamentais para um procedimento restaurador adequado.

A busca foi desenvolvida, por três pesquisadores distintos, através da análise de artigos obtidos na base de dados do PubMed, no período de 2015 a 2020. Foram utilizados descritores devidamente cadastrados no MeSH e DeCS, sendo realizadas buscas utilizando o descritor "Composite Resins" combinado através do operador booleano AND com cada um dos seguintes descritores: "Anti-Bacterial Agents", "Bulk fill", "Fillers" e "Photoinitiators", resultando em um total de 177 artigos encontrados.

Os critérios de inclusão utilizados foram: artigos que avaliaram a incorporação e/ou a associação de substâncias aos compósitos, a fim de aprimorar as propriedades mecânicas: resistência, grau de conversão, grau de estresse de polimerização, bem como também na configuração das propriedades ópticas, sendo estudos in vitro. Eliminaram-se as revisões de literatura simples, os estudos indisponíveis e os que não abordaram o tema em questão. Portanto, após leitura crítica de títulos e resumos, 
Research, Society and Development, v. 10, n. 3, e10110313099. 2021

(CC BY 4.0) | ISSN 2525-3409 | DOI: http://dx.doi.org/10.33448/rsd-v10i3.13099

foram incluídos 11 estudos in vitro, na língua inglesa (Figura 1).

Figura 1: Fluxograma metodológico para a busca realizada na base de dados PubMed.

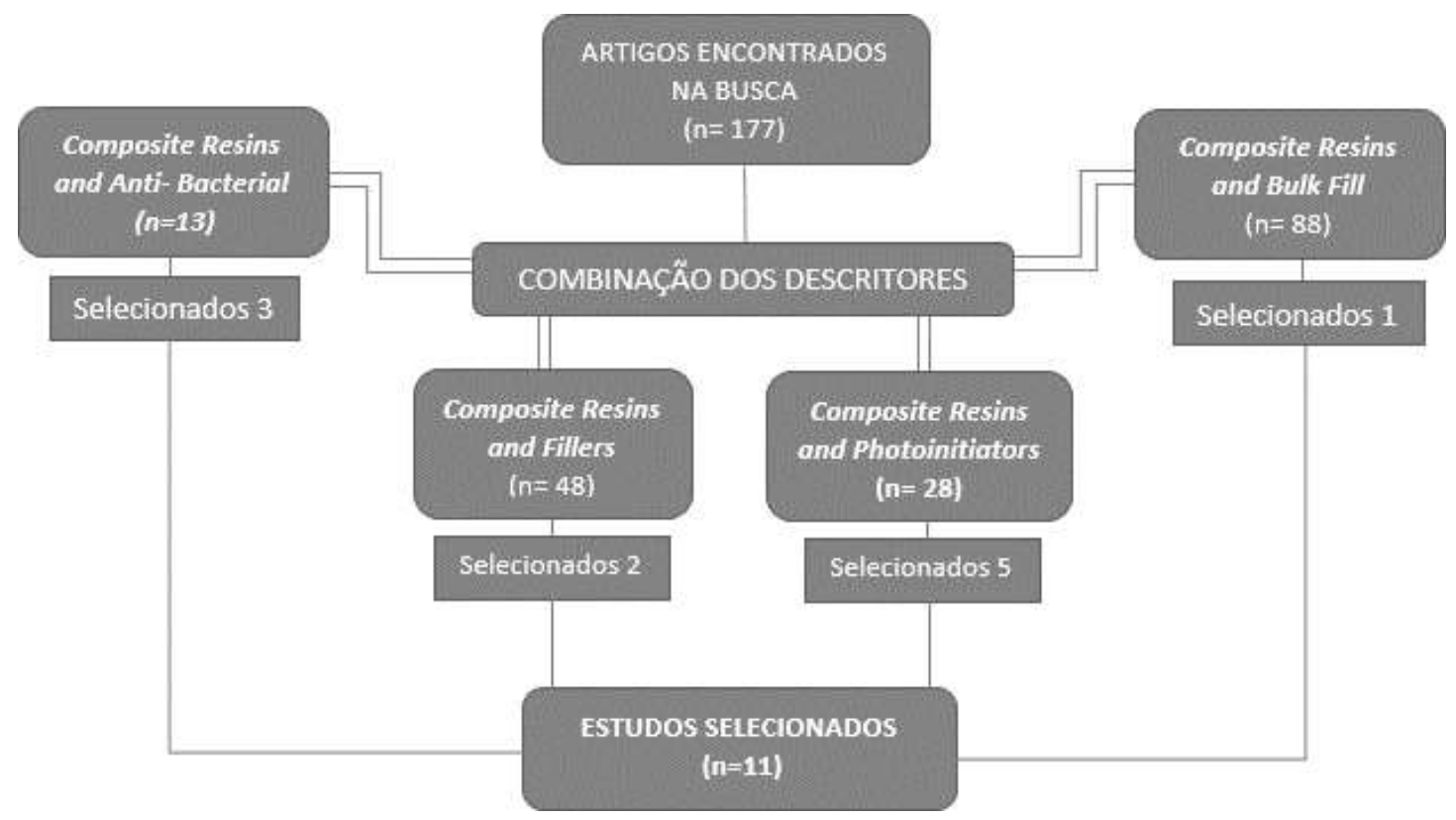

Fonte: Autores (2021).

Na Figura 1 é detalhada a estratégia de busca utilizada para a busca dos artigos na base de dados, evidenciando a quantidade de estudos encontrados e selecionados para a síntese qualitativa neste estudo. 


\section{Resultados}

Tabela 1. Estudos selecionados para a revisão após a aplicação dos critérios de inclusão.

\section{AUTOR/ANO \\ GRUPOS \\ MÉTODOS \\ RESULTADOS}

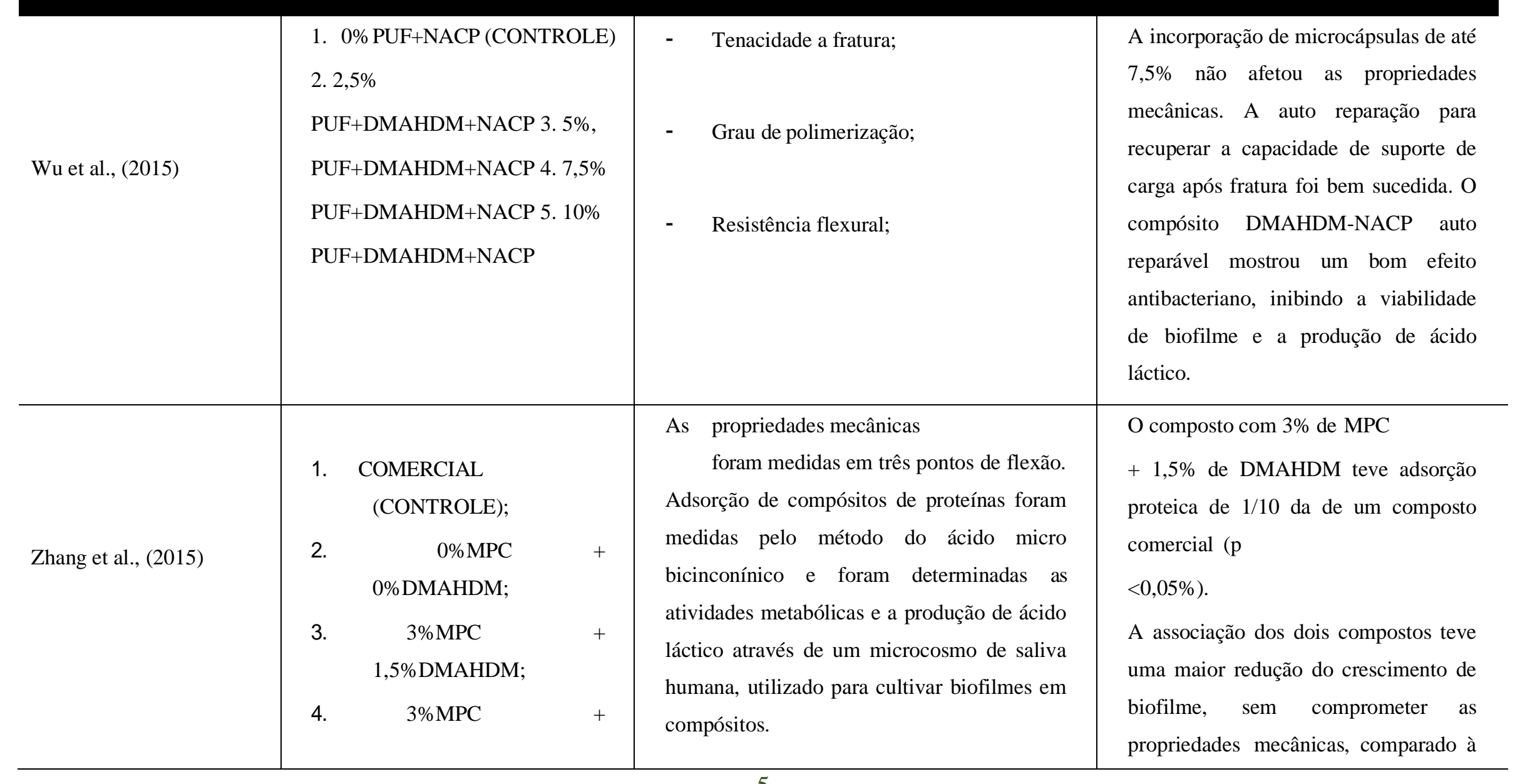


Research, Society and Development, v. 10, n. 3, e10110313099. 2021

(CC BY 4.0) | ISSN 2525-3409 | DOI: http://dx.doi.org/10.33448/rsd-v10i3.13099

\begin{tabular}{|c|c|c|c|}
\hline & $\begin{array}{c}\text { 2,25\%DMAHDM; } \\
\text { 5. } 3 \% \mathrm{MPC}+3 \% \text { DMAHDM }\end{array}$ & & utilização dos mesmos isoladamente. \\
\hline Wu et al., (2016) & $\begin{array}{l}\text { 1. } 0 \% \text { PUF + TEGDMA + } \\
\text { DHEPT 2,5\% } \\
\text { 2. TEGDMA + DHEPT } 5 \% \\
\text { 3. PUF + TEGDMA+DHEPT } \\
7,5 \% \\
\text { 4. PUF + TEGDMA + DHEPT } \\
\text { 10\% } \\
\text { 5. PUF + TEGDMA + DHEPT }\end{array}$ & $\begin{array}{l}\text { As microesferas de Poli ureia-formaldeído } \\
\text { (PUF) foram sintetizadas e encapsuladas em } \\
\text { um líquido de cicatrização composto por } \\
\text { Dimetacrilato de trietileno glicol (TEGDMA) } \\
\text { e N, } \\
\text { Ndihidroxietil-p-toluidina (DHEPT). Foi } \\
\text { medida a resistência a flexão e modo de } \\
\text { elasticidade, além da tenacidade à fratura } \\
\text { (CCI) e a eficácia de autopolimerização. }\end{array}$ & $\begin{array}{l}\text { Até } 7,5 \% \text { de incorporação de } \\
\text { microcápsulas à resina, alcançou uma } \\
\text { auto cura eficaz sem efeitos adversos } \\
\text { nas propriedades mecânicas. }\end{array}$ \\
\hline Aljabo et al., (2016) & $\begin{array}{l}\text { 1. UDMA+CaP0\%+CHX } \\
\text { 2. UDMA+CaP10\%+CHX } \\
\text { 3. UDMA+CaP } 20 \%+\mathrm{CHX} \\
\text { 4. UDMA+CaP } 40 \%+\mathrm{CHX}\end{array}$ & $\begin{array}{l}\text { Para avaliar a morfologia e a composição } \\
\text { elementar da camada precipitada, empregou- } \\
\text { se Microscopia Eletrônica de Varredura } \\
\text { (MEV) com análise de raiox X dispersivos } \\
\text { em energia (EDX) e a espectroscopia Raman } \\
\text { foi utilizada para quantificas ainda mais } \\
\text { quaisquer alterações na superfície e formação } \\
\text { de hidroxiapatita. }\end{array}$ & $\begin{array}{l}\text { As precipitações de HA mostraram } \\
\text { retardar a liberação de } \mathrm{CHX} \text { e } \\
\text { aprisionar este antibacteriano dentro da } \\
\text { camada de hidroxiapatita. }\end{array}$ \\
\hline
\end{tabular}


Research, Society and Development, v. 10, n. 3, e10110313099. 2021

(CC BY 4.0) | ISSN 2525-3409 | DOI: http://dx.doi.org/10.33448/rsd-v10i3.13099

\begin{tabular}{|c|c|c|c|}
\hline Oliveira et al., (2016) & $\begin{array}{ll}\text { 1. } & \mathrm{CQ} \\
\text { 2. } & \mathrm{PPD} \\
\text { 3. } & \mathrm{CQ}+\mathrm{PPD}\end{array}$ & 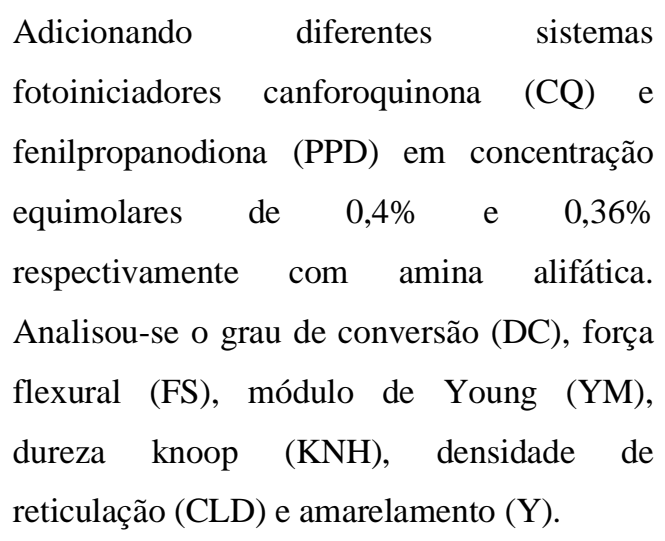 & $\begin{array}{l}\text { Não foram encontradas diferenças } \\
\text { estatísticas entre os grupos nas } \\
\text { propriedades analisadas. A associação } \\
\text { de PPD/CQ mostrou maiores valores de } \\
\text { DC quando fotoativado por um LED de } \\
\text { ondas polares. Os valores de Y foram } \\
\text { maiores em comparação ao sistema } \\
\text { PPD. }\end{array}$ \\
\hline Khovostenko et al., (2016) & $\begin{array}{l}\text { 1. } 15 \mathrm{BAG} \\
\text { 2. } 0 \mathrm{BAG}\end{array}$ & $\begin{array}{l}\text { Foram utilizados dois compósitos diferentes } \\
\text { com } 72 \% \text { de peso de enchimento, um com } \\
15 \% \text { em peso de BAG (15BAG) e o vidro de } \\
\text { estrôncio silanizado de equilíbrio e outro com } \\
\text { sílica aerossol e vidro de estrôncio silanizado } \\
\text { sem BAG (0BAG). }\end{array}$ & $\begin{array}{l}\text { A profundidade média da penetração } \\
\text { bacteriana na lacuna marginal para as } \\
\text { amostras } 15 \mathrm{BAG} \text { foi significativamente } \\
\text { menor ( } \pm 61 \% \text { ) em comparação com } \\
\text { OBAG, onde foi observada } 100 \% \text { de } \\
\text { penetração em todas as amostras com o } \\
\text { biofilme que penetra por baixo da } \\
\text { restauração em alguns casos. }\end{array}$ \\
\hline
\end{tabular}


Research, Society and Development, v. 10, n. 3, e10110313099. 2021

(CC BY 4.0) | ISSN 2525-3409 | DOI: http://dx.doi.org/10.33448/rsd-v10i3.13099

\begin{tabular}{|c|c|c|c|}
\hline Manojlovic et al., (2017) & $\begin{array}{ll}\text { 1. } & \text { FIT }+ \text { TPO } \\
\text { 2. } & \text { FIT+CQ } \\
\text { 3. } & \text { BisGMA+TPO } \\
\text { 4. } & \text { BisGMA+CQ }\end{array}$ & $\begin{array}{l}\text { Comparou-se a citotoxicidade e } \\
\text { genotoxicidade do monômero a base de } \\
\text { uretano (FIT-852) e fotoiniciador de óxido de } \\
\text { monoacilfosfina (Lucirin TPO) com bisfenol } \\
\text { convencional, glicidil-metacrilato (BisGMA) } \\
\text { e sistema fotoiniciador de CQ. As quatro } \\
\text { misturas foram testadas em fibroblastos } \\
\text { pulmonares fetais humanos MRC-5 usando } \\
\text { ensaios MTT e Cometa. }\end{array}$ & $\begin{array}{l}\text { As misturas baseadas em FIT exibiram } \\
\text { efeitos citotóxicos antagônicos entre os } \\
\text { componentes, enquanto as misturas } \\
\text { baseadas em BisGMA demonstraram } \\
\text { efeitos sinérgicos. }\end{array}$ \\
\hline Cardoso et al., (2017) & $\begin{array}{l}\text { 1. QTH (Optillux 501) } \\
\text { 2. Segunda geração LED (Readll } \\
\text { Plus) } \\
\text { 3. Terceira geração LES } \\
\text { (Bluephase G2) }\end{array}$ & $\begin{array}{l}\text { Compósitos de resina bulkfill à base de resina } \\
\text { elastomérica (TFM's) experimentais foram } \\
\text { preparados misturando o metacrilato de zinco } \\
\text { (ZM) com monômeros, co-monômeros, } \\
\text { fotoiniciador e carga. Comparou-se os TFM's } \\
\text { incorporados com ZM ao Fermit-N, a } \\
\text { presença } \\
\text { sorção/solubilidade em água, grau de } \\
\text { conversão, resistência à tração final e dureza. }\end{array}$ & $\begin{array}{l}\text { A eficácia do fotopolimerizador de } \\
\text { terceira geração forneceu uma } \\
\text { polimerização ideal de compósitos } \\
\text { resinosos baseados em Lucirin TPO nas } \\
\text { condições mais testadas, enquanto a } \\
\text { unidade de cura de LED de segunda } \\
\text { geração foi inútil, independentemente } \\
\text { da exposição radiante. }\end{array}$ \\
\hline
\end{tabular}


Research, Society and Development, v. 10, n. 3, e10110313099. 2021

(CC BY 4.0) | ISSN 2525-3409 | DOI: http://dx.doi.org/10.33448/rsd-v10i3.13099

\begin{tabular}{|c|c|c|c|}
\hline Vaidyanathan et al., (2019) & $\begin{array}{l}\text { 1. BisGMA-TEGDMA+TPO } \\
\text { 2. BisGMA- } \\
\text { TEGDMA+CQ/amina }\end{array}$ & $\begin{array}{l}\text { Foi utilizada a espectroscopia Raman para } \\
\text { companhar a conversão durante a } \\
\text { polimerização de BisGMA-TEGDMA } \\
\text { usando óxido de difenil (2, 4, } 6 \text { dimetilben- } \\
\text { zoyl) fosfina tipo } 1 \text { e CQ e uma amina como } \\
\text { fotoiniciador tipo } 2 \text {. }\end{array}$ & $\begin{array}{l}\text { Em relação ao tempo de exposição, } \\
\text { houve uma diferença significativa de } \\
\text { TPO e CQ/amina (TPO com } 5 \mathrm{~s} \text { e } \\
\text { CQ/amina 20s). Também houve uma } \\
\text { diferença significativa no efeito do } \\
\text { tempo de armazenamento (nenhum } \\
\text { efeito no TPO vs uma maior } \\
\text { porcentagem de conversão com } \\
\text { CQ/amina). }\end{array}$ \\
\hline Peralta et al., (2019) & $\begin{array}{l}\text { 0ZM+TFM'S (controle) } \\
\text { 1\%ZM+TFM'S } \\
\text { 2\%ZM+TFM'S } \\
\text { 5\%ZM+TFM'S }\end{array}$ & $\begin{array}{l}\text { Compósitos de resina bulkfill à base de } \\
\text { TFM's experimentais foram preparados } \\
\text { misturando o ZM com monômeros, co- } \\
\text { monômeros, fotoiniciador e cargas. } \\
\text { Comparou-se os TFM's incorporados com } \\
\text { ZM ao Fermit-N, a presença de } \\
\text { microinfiltração, sorção/solubilidade em } \\
\text { água, grau de conversão, resistência à tração } \\
\text { final e dureza. }\end{array}$ & $\begin{array}{l}\text { Os resultados mostraram que as } \\
\text { propriedades físicas e mecânicas } \\
\text { dos TFM's experimentais com ZM } \\
\text { são comparáveis com as referências } \\
\text { comerciais. Algumas propriedades } \\
\text { foram melhoradas e mostraram } \\
\text { menor infiltração e sorção à água e } \\
\text { maior resistência à tração. TFMs } \\
\text { com ZM destruíram o biofilme } \\
\text { induzido somente após 1h. O } \\
\text { desenvolvimento do biofilme de S. } \\
\text { mutans não foi afetado pela } \\
\text { inclusão de ZM nos TFMs } \\
\text { experimentais. }\end{array}$ \\
\hline
\end{tabular}


Research, Society and Development, v. 10, n. 3, e10110313099. 2021

(CC BY 4.0) | ISSN 2525-3409 | DOI: http://dx.doi.org/10.33448/rsd-v10i3.13099

\begin{tabular}{|c|c|c|c|}
\hline Andrade et al., (2020) & $\begin{array}{ll}\text { 1. } & \mathrm{CQ} \\
\text { 2. } & \mathrm{CQ} / \mathrm{Amina}+\mathrm{TPO}\end{array}$ & 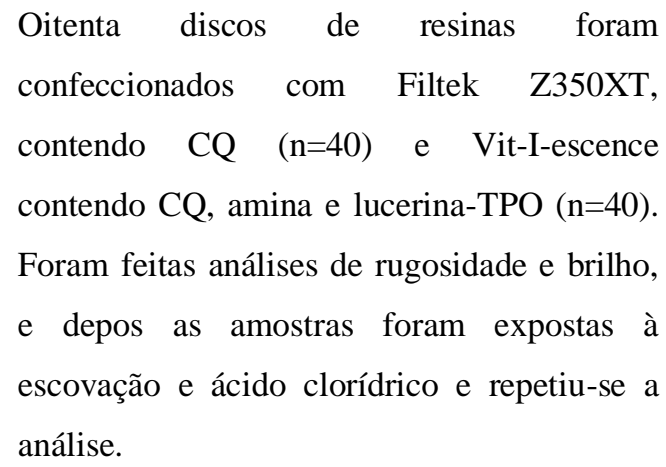 & $\begin{array}{l}\text { Todas as resinas apresentaram } \\
\text { diminuição significativa no brilho } \\
\text { após os desafios. O tipo de } \\
\text { dispositivo de LED não influenciou } \\
\text { a rugosidade e o brilho da superfície } \\
\text { dos compósitos de resina para } \\
\text { dentes clareados apóes os testes. }\end{array}$ \\
\hline
\end{tabular}

Fonte: Autores (2021).

Na Tabela 1 são demonstrados os principais resultados obtidos pelos estudos selecionados para esta revisão de literatura, assim como os grupos e composições de RCs testadas e os métodos utilizados para a realização dos testes. 
Research, Society and Development, v. 10, n. 3, e10110313099. 2021

(CC BY 4.0) | ISSN 2525-3409 | DOI: http://dx.doi.org/10.33448/rsd-v10i3.13099

\section{Discussão}

Fratura e infiltração bacteriana são um dos principais motivos de falha na restauração dentária. Wu et al. (2014), através um estudo in vitro, objetivaram desenvolver um compósito auto-reparável no qual foi preenchido com dimetilaminohexadecila (DMAHDM) para o aprimoramento da ação antibacteriana, NACP para remineralização e liberação de íons Ca e P e partículas de vidro para reforço das propriedades mecânicas, além de serem incorporados por microcápsulas (PUF) contendo TEGDMA-DHEPT como agente iniciador de autopolimerização. Ainda, foi observado após os testes que a resistência flexural e o módulo de elasticidade do compósito não foram significativamente reduzidos pela adição de até 7,5\% de microcápsulas, tenacidade a fratura obteve um resultado alcançando um KIC de 65-81\%, que é consistente com o estudo anterior de Henghua et al. (2011), que relatam uma recuperação de 57\% da tenacidade. No que confere a atividade antimicrobiana a adição de DMAHDM, inibiu a ação metabólica e a produção de ácido láctico pelo biofilme.

Zhang et al. (2015), por sua vez, objetivou potencializar um compósito homogeneizando-o com a combinação de metacriloiloxietil fosforilcolina (MPC) e dimetilaminohexadecila (DMAHDM) visando avaliar atividade antibacteriana e repelente de proteínas, bem como também no que confere as configurações das propriedades mecânicas. Foi observado que o material com a combinação de 3\% de MPC + 1,5\% de DMAHDM demonstrou ser promissor para realização de restaurações dentárias devido os resultados de resistência flexural e módulo de elasticidade terem sido favoráveis, não interferindo na resistência do compósito. Com isso, os resultados do ensaio metabólico (MTT) e ácido láctico também se mostraram positivos, corroborando assim com o estudo de $\mathrm{Wu}$ et al. (2015), evidenciando a eficácia do metacrilato DMAHDM, possibilitando a ação antimicrobiana efetiva inibindo a produção de biofilme e ação repelente de proteínas.

Melhorar a resistência à fratura de compósitos dentários é de grande importância e esforços de grande valia vem sendo realizados para a melhoria das propriedades mecânicas das resinas convencionais e bulk fill. Diante desse contexto, Wu et al. (2016), propôs a elaboração de um material autoreparável incorporado com microcápsulas de poli ureia-formaldeído (PUF) preenchidas por um liquido de um agente polimérico (DHEPT), no qual a propagação da força mastigatória fez com que as cápsulas incorporadas ao compósito rompessem liberando o agente e reparando as possíveis áreas de fratura. Ainda, esse estudo fundamentou a hipótese dos estudos anteriores, evidenciando o uso de que até 7,5\% em peso de microcápsulas de PUF associadas de um fluído polimérico eficaz, não iria interferir nas propriedades mecânicas, constatando isso com os resultados positivos dos testes de resistência a flexão e modo de elasticidade, e além disso, legitimou-se que o envelhecimento do compósito em água durante 6 meses não interferiu na ação polimérica das microcápsulas.

Aljabo et al. (2016), buscaram produzir um compósito dentário de ampla resistência que liberasse fosfato de cálcio $(\mathrm{CaP})$ e clorexidina $(\mathrm{CHX})$ e que adicionalmente promovessem a precipitação de hidroxiapatita (HA). Após a MEV, observouse que a porcentagem da superfície coberta por HA e o tamanho médio das esferas de HA aumentaram progressivamente com o prolongamento do teor de CaP nas amostras. No Raio-X de energia dispersiva (EDX), o mapeamento completo da superfície compostas mostrou que a proporção de Ca (principalmente de HA) cresceu linearmente com o tempo de armazenamento no fluído corporal simulado (SBF) entre 1 e 30 dias. Diante desses resultados, a incorporação de CaP em compósitos dentários promoveu a precipitação proporcional de HA no SBF. Ademais, verificou-se que a CHX estava ligada a precipitação de HA em alta concentração. Por fim, evidenciaram a eficácia do compósito estudado, no qual obtiveram um material potencialmente qualificado para resolução de microinfiltrações, bem como também, proporcionar a remineralização de dentina desmineralizada.

Oliveira et al. (2016), estudaram a fenilpropanodiona (PPD) como um fotoiniciador alternativo, a fim de diminuir o amarelamento causado pela $\mathrm{CQ}$, devido à sua cor menos amarelada em comparação com a Canforoquinona (CQ). Além disso, 
Research, Society and Development, v. 10, n. 3, e10110313099. 2021

(CC BY 4.0) | ISSN 2525-3409 | DOI: http://dx.doi.org/10.33448/rsd-v10i3.13099

objetivaram avaliar as propriedades ópticas e químico-mecânicas de compósitos contendo PPD em sua composição comparativamente com CQ. Inferiu-se por meio do grau de conversão (DC) e resistência flexural (FS), que não foram encontradas diferenças estatísticas entre os diferentes sistemas fotoiniciadores. No entanto, a associação PPD+CQ apresentou os maiores valores de DC e FS em comparação com os sistemas isolados. Além disso, por meio de CLD e Y constatou-se que a PPD isolada, foi capaz de reduzir o amarelamento dos compósitos e também promover propriedades químicas e mecânicas semelhantes ou superiores em comparação com a CQ. Portanto, a PPD é um fotoiniciador alternativo promissor em comparação com a $\mathrm{CQ}$, pois melhora a estabilidade de cor sem comprometer as propriedades químicas ou mecânicas das resinas, legitimando estudos anteriores como o de Brandt et al. (2011), na qual obtiveram resultados semelhantes ao presente estudo.

Khovostenko et al. (2016), investigaram o efeito da adição de 15\% em peso de biovidro (BAG) a um compósito, para averiguar suas propriedades antimicrobianas e remineralizadoras. As amostras restauradas e com fendas propositalmente formadas, tiveram Streptococcus mutans crescidos na superfície e foram testados dentro de um biorreator por duas semanas enquanto sujeitos a períodos de carga mecânica cíclica. Foi observado um grau significativamente mais baixo de penetração bacteriana na fenda para amostras restauradas com resina composta incorporadas com 15\% de BAG. Em média, para o compósito 15BAG, a penetração foi de $\cong 61 \%$ da profundidade da fenda e para as amostras do grupo controle sem BAG, o grau de penetração bacteriana nas lacunas era consistentemente muito profundo, atingindo o fundo da cavidade. Deste modo, compósitos dentários de resina integrados de BAG reduziram a penetração de bactérias em espaços marginais de restaurações dentárias simuladas, reafirmando que o BAG pode ter o potencial de retardar o desenvolvimento e a propagação da cárie dentária secundária.

No estudo de Manojlovic et al. (2017), as hipóteses testadas foram descartadas, uma vez que os monômeros fotoativadores e seus compostos podem exercer implicações genotóxicas e citotóxicas divergentes. Além disso, possuem a capacidade de interagir de acordo com os seus componentes entre si, acarretando alterações no total de toxicidade. Ademais, os componentes que não são aptos de reagir durante sua aplicabilidade e processo de polimerização, principalmente no período inicial de 24 horas, podem ocasionar efeitos indesejáveis aos tecidos vitais. Vários estudos publicados na literatura corroboram com essa perspectiva, uma vez que a citotoxicidade costuma ser observada após 24 horas de realização do procedimento (DURNER et al., 2012; LAURENT et al., 2008). No entanto, mesmo com essas observações ainda é muito pequeno o número de estudos disponíveis na literatura acerca dos efeitos citotóxicos e genotóxicos associados com a composição de materiais dentários, fazendo com que os achados existentes até o momento se tornem pouco conclusivos.

Há um consenso na literatura que a irradiância dos fotopolimerizadores está relacionada com a conversão dos monômeros em polímeros e durabilidade das restaurações estéticas (MARSON et al., 2010). O estudo realizado por Cardoso et al. (2017) buscou fazer uma comparação entre a eficácia do aparelho LED de segunda geração e LED de terceira geração, onde observou-se que esse último promoveu uma polimerização mais adequada. Estudos atuais afirmam que uma polimerização eficiente ocorre a partir da utilização de um aparelho que apresente IR em torno de $400 \mathrm{~mW} / \mathrm{cm}^{2}$ e o LED de terceira geração se mostra eficaz, pois possui IR de 1.500 a $2.000 \mathrm{~mW} / \mathrm{cm}$. Em contrapartida, o LED de segunda geração se mostra ineficaz, uma vez que sua IR está em torno de $300 \mathrm{~mW} / \mathrm{cm}^{2}$ (BORGES et al., 2011). Já Andrade et al. (2020), utilizaram um LED de micro-ondas e um LED de ondas polares para a fotoativação de espécimes de resina composta Filtek Z350XT e Vit-l-escence, ambas contendo Canforoquinona (CQ). Após a análise de rugosidade e brilho dos espécimes, foi constatado que o tipo dispositivo LED não influenciou essas características.

Vaidyanath et al. (2017), utilizaram a espectroscopia Raman para comparar a capacidade de conversão monomérica de BIsGMA-TEGDMA incorporado com dois fotoiniciadores diferentes: óxido de difenil fosfina e a CQ. A CQ é um 
Research, Society and Development, v. 10, n. 3, e10110313099. 2021

(CC BY 4.0) | ISSN 2525-3409 | DOI: http://dx.doi.org/10.33448/rsd-v10i3.13099

fotoiniciador bastante descrito na literatura, sendo considerado como o "padrão-ouro", uma vez que está presente na maioria das resinas compostas e se mostra capaz de ser ativada por uma grande quantidade de fotopolimerizados (Karbhari \& Strassler, 2007). Porém, no presente estudo foi constatado que a fotopolimerização do BisGMA se mostrou muito mais eficiente com óxido de difenil fosfina do que com a CQ, além disso, o tempo de exposição influenciou fortemente na conversão da CQ, ao contrário do óxido de difenil fosfina, demostrado outra característica satisfatória desse fotoiniciador. Isso pode ser justificado devido aos componentes que o óxido de difenil fosfina apresenta, Cadenaro et al. (2010) relataram que fatores como hidrofilicidade e conteúdo de solvente dessas formulações desempenham um papel significativo no grau de conversão.

Peralta et al. (2019) investigaram os aspectos físicos e mecânicos, além propriedades antibacterianas e biocompatibilidade de novos compósitos Bulk Fill (BK) à base de componentes elastoméricos temporários contendo Metacrilato de Zinco (MZ). Com isso, foram observadas algumas propriedades melhoradas, como menor infiltração e maior sorção de água, além de aumento dos valores de resistência à tração final. Além disso, o desenvolvimento do biofilme de Streptococcus mutans não foi afetado pela inclusão de MZ. Com relação a sorção de água, isso é justificado provavelmente devido à presença de Zinco, formando uma rede de ligações de Hidróxido de Zinco nas cadeias poliméricas na presença de água.

\section{Considerações Finais}

Desse modo, observou-se uma positiva e eficaz evolução dos compósitos resinosos favorecendo as propriedades físicas e químicas. Entretanto não há uma unanimidade de qual compósito garante suprimir todas as limitações.

Assim, faz-se necessário a realização de mais estudos nesta temática a fim de confirmar a eficácia total da melhoria das propriedades dos materiais resinosos com diferentes composições e inovações.

\section{Referências}

Aljabo, A., Neel, E. A. A., Knowles, J. C. \& Young, A. M. (2016). Development of dental composites with reactive fillers that promote precipitation of antibacterial-hydroxyapatite layers. Materials Science and Engineering. 60, 285-292.

Andrade, K. C., Pini, N. I. P., Moda, M. D., Ramos, F. S. S., Santos, P. H., Briso, A. L. F. \& Fagundes, T. C. (2020). Influence of different light-curing units in surface roughness and gloss of resin composites for bleached teeth after challenges. Journal of the mechanical behavior of biomedical materials. 102 , 103458.

Bertolo, M. V., Moraes, R. C., Pfeifer, C., Salgado, V. E., Correr, A. R \& Schneider, L. F. (2017). Influence of Photoinitiator System on Physical-Chemical Properties of Experimental Self-Adhesive Composites. Braz. Dent. J. 28(1), 35-39.

Borges, F. M. G. S., Rodrigues, C. C., Freitas, S. A. A., Costa, J. F. \& Bauer, J. (2011). Avaliação da intensidade de luz dos fotopolimerizadores utilizados no curso de Odontologia da Universidade Federal do Maranhão. Revista Ciência Saúde. 13(1), 26-30.

Brandt, W. C, Toamselli, L. O., Correr-Sobrinho, L. \& Sinhoreti, M. A. C. (2011). Can phenyl-propanedione influence Knoop hardness, rate of polymerization and bond strength of resin composite restorations? Journal of dentistry. 39(6), 438-447.

Cadenaro, M., Antoniolli, F., Codan, B., Agree, K., Tay, F. R., Dorigo, E. S., Pashley, D. H. \& Breschi, L. (2010). Influence of different initiators on the degree of conversion of experimental adhesive blends in relation to their hydrophilicity and solvent content. Denal materials. $26,288-294$.

Cardoso, K. A. O. R., Zarpellon, D. C., Madruga, C. F. L., Rodrigues, J. A. \& Arrais, C. A. G. (2017). Effects of radiant exposure values using second and third generation light curing units on the degree of conversion of a lucirin-based resin composite. Journal of Applied Oral Science. 25(2), 140-146.

Cramer, N. B., Stansbury, J. W. \& Bowman, C. N. (2011). Recent advances and developments in composite dental restorative mate rials. Journal of dental research. 90(4), 402-416.

Da Silva, F. J. V., Da Silva, E. L., Januário, M. V. S., Vasconcelos, M. G. \& Vasconcelos, R. G. (2017). Técnicas para reduzir os efeitos da contração de polimerização das resinas compostas fotoativadas. Salusvita. 36(1), 187-203

Durner, J., Wellner, P., Hickel, R. \& Reichl, F. X. (2012). Synergisticinteraction caused to human gingival fibroblasts fromd ental monomers. Dental materials. 28(8), 818-823.

Ferracane, J. L. (2011). Resin composite—state of the art. Dental materials. 27(1):29-38. 
Research, Society and Development, v. 10, n. 3, e10110313099. 2021

(CC BY 4.0) | ISSN 2525-3409 | DOI: http://dx.doi.org/10.33448/rsd-v10i3.13099

Guimaraes, G. F., Marcelino, E., Cesarino, I., Vicente, F. B., Grandini, C. R. \& Simões, R. P. (2018). Minimization of polymerization shrinkage effects on composite resins by the control of irradiance during the photoactivation process. Journal of Applied Oral Science. 26.

Jin, H, Miller, G. M., Sottos, N. R. \& White, S. R. (2011). Fracture and fatigue response of a self-healing epoxy adhesive. Polymer. 52(7), $1628-1634$.

Karbhari, V. M. \& Strassler, H. (2007). Effect of fiber architecture on flexural characteristics and fracture of fiber-reinforced dental composites. Dental Materials. 23(8), 960-968.

Khvostenko, D., Hilton, T. J., Ferracane, J. L., Mitchell, J. C. \& Kruzic, J. J. (2016). Bioactive glass fillers reduce bacterial penetration into marginal gaps for composite restorations. Dental Materials. 32(1), 73-81.

Laurent, P., Camps, J., De Méo, M., Déjou, J. \& About, I. (2008). Induction ofspecific cell responses to a Ca(3)SiO(5)-based posteriorrestorative material. Dental materials. 24(11), 1486-1494.

Lin, J., Sun, M., Zheng, Z., Shinya, A., Han, J., Lin, H., Zheng, G. \& Shinya, A. (2013). Effects of rotating fatigue on the mechanical properties of microhybrid and nanofiller-containing composites. Dental materials journal. 32(3), 476-4783.

Machado, A. L. S. (2018). Influência da incorporação de silicato de nióbio como carga inorgânica para uma resina composta. XXX Salão de Iniciação Científica, Universidade Federal do Rio Grande do Sul.

Manojlovic, D., Dramicanin, M. D., Miletic, V., Mitic-Culafic, D., Jovanovic, B. \& Nikolic, B. (2017). Cytotoxicity and genotoxicity of a low-shrinkage monomer and monoacylphosphine oxide photoinitiator: Comparative analyses of individual toxicity and combination effects in mixtures. Dental Materials. $33(4), 454-466$

Marson, F. C., Mattos, R. \& Sensi, L. G. (2010). Avaliação das condições de uso dos fotopolimerizadores. Revista Dentística online-ano. 9(19), 15-20.

Oliveira, D. C. R. S., Souza-Junior, E. J., Dobson, A., Correr, A. R. C., Brandt, W. C. \& Sinhoreti, M. A. C. (2016). Evaluation of phenyl- propanedione on yellowing and chemical-mechanical properties of experimental dental resin-based materials. Journal of Applied Oral Science. 24(6), 555-560.

Peralta, S. L., Dutra, A. L., Leles, S. B., Ribeiro, J. S., Ogliari, F. A., Piva, E. \& Lund, R. G. (2019). Development and characterization of a novel bulk-fill elastomeric temporary restorative composite. Journal of Applied Oral Science. 27.

Pereira, A. S., Shitsuka, D. M., Parreira, F. J. \& Shitsuka, R. (2018). Metodologia da pesquisa científica. UFSM.

Reis, A. \& Loguercio, A. D. (2007). Materiais dentários diretos: dos fundamentos à aplicação clínica. São Paulo: Santos Editora.

Silva, S. B. (2011). Resistência à fadiga e propensão a trincas em restaurações amplas de resina composta em dentes posteriores. Repositório Institucional, Universidade Federal do Santa Catarina.

Sinhoreti, M. A., Oliveira, D. C., Rocha, M. G. \& Roulet, J. F. (2018). Light-curing of resin-based restorativ'e materials: an evidence-based approach to clinical practice application. Clin Dent Res. 15(1), 44-53.

Souza, M. B. A., Oliveira, O., Moda, M. D., Santos, P. H., Briso, A. L. F. \& Fagundes T. C. (2017). OPPg o32-Influência de diferentes tipos de fotopolimerizadores e fotoiniciadores na microdureza e cor de resinas compostas. Archives of Health Investigation. 6.

Vaidyanathan, T. K., Vaidyanathan, J., Lizymol, P. P., Ariya, S. \& Krishnan, K. V. (2017). Study of visible light activated polymerization in BisGMATEGDMA monomers with type 1 and type 2 photoinitiators using Raman spectroscopy. Dental Materials. 33(1), 1-11.

Wu, J., Weir, M. D., Melo, M. A. S. \& Xu, H. H. K. (2015). Development of novel self-healing and antibacterial dental composite containing calcium phosphate nanoparticles. Journal of dentistry. 43(3), 317-326.

Wu, J., Weir, M. D., Melo, M. A. S., Strassler, H. E. \& Xu, H. H. K. (2016). Effects of water-aging on self-healing dental composite containing microcapsules. Journal of dentistry.47,86-93.

Zhang, N., Ma, J., Melo, M. A. S., Weir, M. D., Bai, Y. \& Xu, H. H. K. Protein-repellent and antibacterial dental composite to inhibit biofilms and caries. Journal of dentistry. 43(2), 225-234.

Yamamoto, E. T. C., Uemura, E. S., Maekawa, M. Y., Bagni, B. A., Rosa, R. G. S. \& Destro, A. S. S. (2009). Avaliação da resistência flexural de resinas acrílicas polimerizadas por dois métodos. Revista Sul-Brasileira de Odontologia. 6(2), 147-154. 